\title{
Mediodorsal Thalamic Lesions Impair Trace Eyeblink Conditioning in the Rabbit
}

\author{
Donald A. Powell ${ }^{1-4}$ and John Churchwell ${ }^{1,2}$ \\ ${ }^{1}$ Shirley L. Buchanan Neuroscience Laboratory, Dorn VA Medical Center and ${ }^{2}$ Department of Psychology, University of South Carolina, \\ Columbia, South Carolina 29208, USA ${ }^{3}$ Department of Neuropsychiatry and Behavioral Science, University of South Carolina School \\ of Medicine, Columbia, South Carolina 29208, USA
}

\begin{abstract}
Rabbits received lesions of the mediodorsal nucleus of the thalamus (MDN) or sham lesions and were subjected to classical eyeblink (EB) and heart rate (HR) conditioning. All animals received trace conditioning, with a .5 -sec tone conditioned stimulus, a .5 -sec trace period, and a 50-msec periorbital shock unconditioned stimulus. Animals with MDN lesions acquired the EB conditioned response (CR) more slowly than sham-lesioned animals. However, previous studies have shown that MDN damage does not affect delay conditioning using either .5-sec or 1-sec interstimulus intervals. The lesions had no significant effect on the HR CR. These results suggest that information processed by MDN and relayed to the prefrontal cortex is required for somatomotor response selection under nonoptimal learning conditions.
\end{abstract}

The mediodorsal nucleus of the thalamus (MDN) is a primary thalamic nucleus providing projections to the prefrontal cortex, and, like the prefrontal cortex, has been implicated in various aspects of learning and memory. We have shown previously that lesions of MDN slightly retard the acquisition of a classically conditioned eyeblink (EB) response (Buchanan and Thompson 1990), but do not affect asymptotic performance. Similar small, although significant, MDN-lesion effects are seen on acquisition of an EB instrumental avoidance response (Buchanan 1994). Much more severe MDN-lesion effects are seen in a discrimination/reversal paradigm, particularly during the reversal phase. Thus, these lesions have little effect on the original acquisition of a discrimination between a reinforced conditioned stimulus (CS+) and a nonreinforced conditioned stimulus (CS-). However, if, after this discrimination has been acquired, the stimuli are reversed such that the previously reinforced CS+ is no longer reinforced and the previously nonreinforced CS- is now the CS+, MDN lesions dramatically impair acquisition of this reversal task (Buchanan 1991). Other investigators have reported similar findings (Gabriel et al. 1989). We have also shown that MDN damage significantly impairs EB conditioning when the interstimulus interval (ISI) is not optimal (i.e., a 2-sec ISI), or during partial reinforcement, when the schedule involves $25 \%$, but not $100 \%$ or $50 \%$ reinforcement (Buchanan et al. 1997b). Further, multiple unit activity recorded from MDN during classical EB conditioning is correlated with acquisition of

${ }^{4}$ Corresponding author.

E-MAIL donnie.powell@med.va.gov; FAX (803) 695-7942.

Article and publication are at http://www.learnmem.org/cgi/doi/ $10.1101 / \mathrm{lm} .45302$. the conditioned response (CR) (Buchanan et al. 1997a), but such changes are relatively small and do not show a clear acquisition function.

These findings suggest that MDN, or its inputs to PFC, may be important for acquisition of the classically conditioned EB response, although not essential. It appears that MDN function may be most critical under conditions of greater task complexity or difficulty, such as discrimination/ reversal or nonoptimal ISI or partial reinforcement conditions, but is less important for relatively simple tasks acquired under optimal conditions. Similar findings have been reported after damage to the hippocampus. Thus, hippocampal damage has little effect on acquisition of a simple eyeblink CR, but dramatically impairs discrimination/reversal conditioning (Buchanan and Powell 1980; Berger and Orr 1983). Hippocampal lesions also impair acquisition of simple classical conditioning acquired with nonoptimal stimulus parameters, for example, trace conditioning (Solomon et al. 1986; Moyer et al. 1990). If MDN is most important in conditioning situations involving greater difficulty or complexity, then MDN damage should also impair simple classical conditioning if less than optimal stimulus parameters are utilized. The present experiments thus examined the effects of MDN lesions on acquisition of the eyeblink CR during trace conditioning. Our early studies also suggested that MDN lesions enhanced the normally occurring bradycardiac heart rate (HR) CR during Pavlovian conditioning, and eliminated a later-occurring tachycardiac component that occurs with longer training, and presumably reflects the execution of the somatomotor EB CRs (Buchanan and Thompson 1990). Thus, the HR CR was also assessed during classical conditioning in the present studies.

LEARNING \& MEMORY 9:10-17 @ 2002 by Cold Spring Harbor Laboratory Press ISSN1072-0502/02 \$5.00

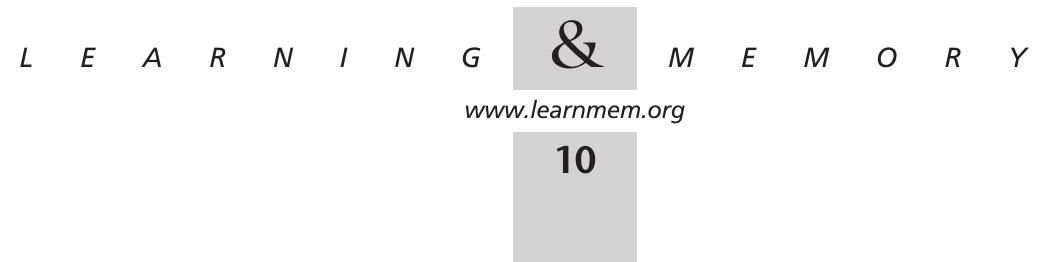




\section{RESULTS}

\section{Histology}

Histological analysis of ibotenic acid-lesioned animals revealed neuronal degeneration and glial proliferation bilaterally in MDN in eight animals. In three of the animals, damage was restricted to the more anterior portions of MDN. In the remaining animals, however, damage extended throughout the nucleus. Minimal damage was seen in several other nuclei adjacent to MDN. Two animals revealed unilateral damage to the anterior nuclei (anterodorsal and anteroventral), the nucleus reuniens, the centromedial nucleus, and the paracentral nucleus. In three animals, paratenial or medioventral damage occurred, and in two animals nucleus reuniens or centromedian damage was observed. Slight bilateral damage was seen in the precentral nucleus $(n=3)$, and in the anteromedial nucleus $(n=3)$. Maximum and minimum damage to the MDN is illustrated in Figure 1. As can be seen, except for the midline nuclei, non-MDN damage was minimal. Moreover, there were no apparent behavioral differences between animals with such damage and those with damage restricted to MDN. As a result of the histological analysis, behavioral data from eight sham (four males and four females) and eight lesioned (three females and five males) animals were subjected to analysis.

\section{Eyeblink}

Comparison of the MDN- and sham-lesioned animals revealed significant group $[\mathrm{F}(1,15)=5.75, P<.03]$ and session $[\mathrm{F}(9,35)=9.1, P<.0001]$ effects. The session effect, of course, reflects the acquisition of the response across sessions. The group effect reflects lower levels of responding in the MDN-lesioned than in the sham-lesioned group. These results can be seen in Figure 2. Although the shape of the acquisition function is normal in the animals with MDN lesions, the rate of acquisition is slower and asymptotic levels are somewhat depressed. During extinction, there was no significant group effect.

Analysis of EB CR amplitude yielded only a significant session effect during acquisition $[\mathrm{F}(9,135)=4.60, P<.0001]$, reflecting an increase in amplitude across sessions. However, neither the group effect $[\mathrm{F} 1,15)=.96, P=.34]$ nor group $\times$ session interaction $[\mathrm{F}(9,135)=1.05, P=.41]$ was significant. There were also no significant effects on this measure during extinction, nor on the latency measure dur-

Figure 1 Diagram of coronal sections through the thalamus of the rabbit showing maximal (hatched) and common (solid) damage to the mediodorsal nucleus of the thalamus (MDN) and adjacent thalamic nuclei. (AM) Anterodorsal nuclei; (AV) anteroventral nucleus; (CM) centromedian nucleus; (IL) intralaminar nuclei; (IMD) intermediodorsal nucleus; (MV) medioventral nucleus; (PAV) paraventricular nucleus; (PF) parafasciular nucleus; (PT) paratenial nucleus; (RE) reunions nucleus; $(\mathrm{VL})$ ventrolateral nucleus; (VM) ventromedial nucleus; (VP) ventroposterior nucleus. ing either acquisition or extinction. The mean EB amplitude was $108.10( \pm 26.4)$ and $124.1( \pm 62.8)$ millivolts for the
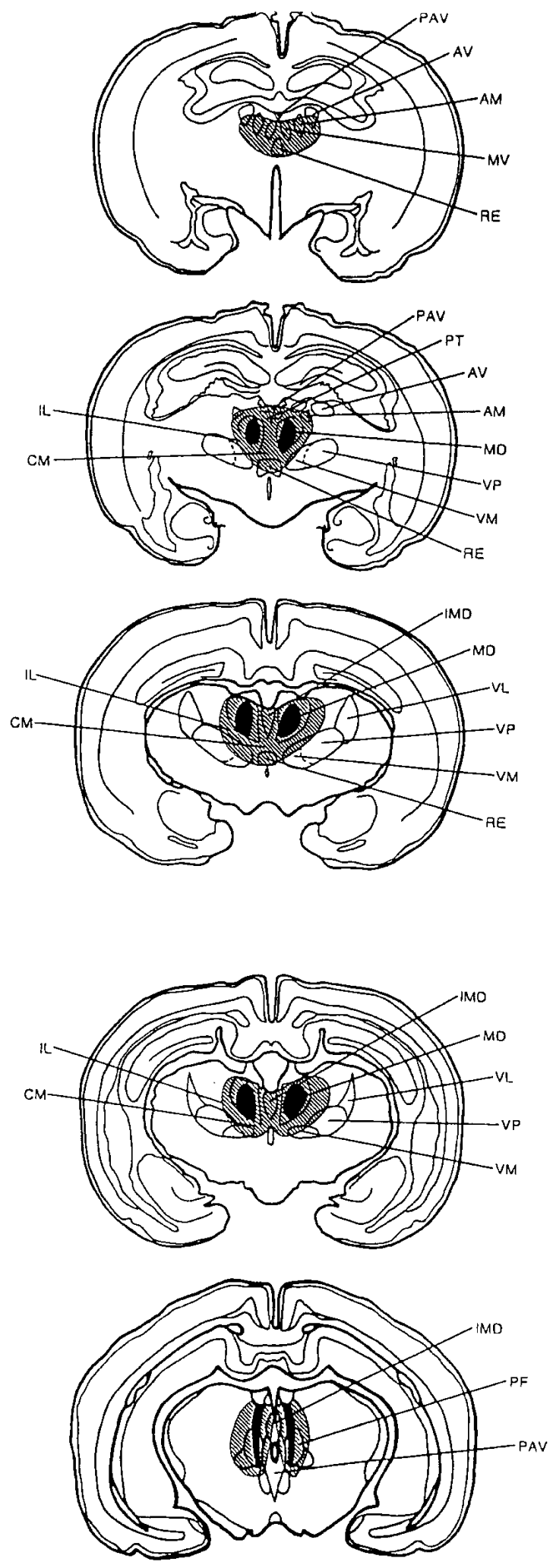

$$
\begin{array}{lllllllllllllll}
L & E & A & R & N & I & N & G & \mathcal{Z} & M & E & M & O & R & Y \\
\text { www.learnmem.org } & & & &
\end{array}
$$




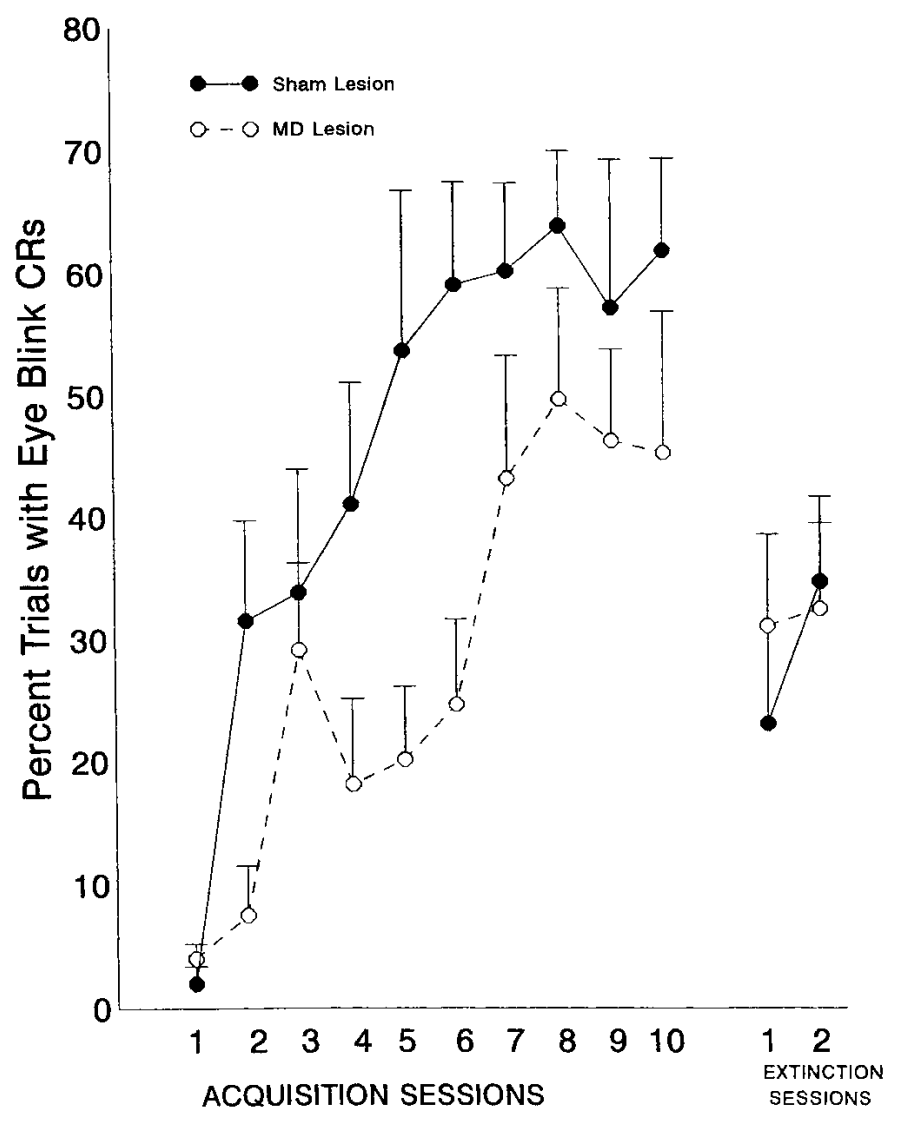

Figure 2 Mean percentage of conditioned eyeblink (EB) responses $( \pm S E)$ in animals with lesions of the mediodorsal nucleus of the thalamus (MDN) or sham lesions. Data are shown as a function of 10 daily acquisition sessions of trace conditioning, in which a .5-sec tone conditioned stimulus was presented, followed by a .5-sec trace period, at which time a 50-msec periorbital shock unconditioned stimulus was presented. Two daily extinction sessions, in which the unconditioned stimulus was omitted, followed the acquisition training. Each session consisted of 60 trials.

sham and lesion groups, respectively. Similar mean CR latencies for the sham and lesion groups was $708( \pm 56.1)$ and $696( \pm 39.6)$ msec. An analysis of UR latency and amplitude also revealed no significant group effects or group interactions.

\section{Heart Rate}

The HR CR is illustrated in Figure 3, which shows mean HR change [in beats per minute (BPM)] across acquisition sessions, separately for the lesion and sham groups. In all animals, the HR CR was the typically obtained deceleration from pre-CS baseline. However, this response was somewhat larger in the animals with MDN damage. They also became somewhat smaller across training sessions and across the four test trials within each session. These changes resulted in significant effects for session $[\mathrm{F}(9,107)=8.8, P<.0001]$, trial $[\mathrm{F}(3,39)=4.68, P<.006]$, and post-CS IBI $[\mathrm{F}(9,117)=3.99, P<.0002]$. However, there were no significant group or group interaction effects during acquisition. Thus, the differences in CR amplitude between the MDN and sham groups shown in Figure 3 did not reach statistical signficance [group $\times$ session interaction: $\mathrm{F}(9,117)=1.62, P=.11]$. During extinction, again, no significant group effects or group interactions were obtained.

\section{Baseline HR}

Separate ANOVAs were conducted on baseline HR. During acquisition, there were significant trial and session effects [smallest $\mathrm{F}(8,137)=4.37, P<.0001$ ] reflecting a decrease in baseline HR across sessions, and across trials within sessions. There were, however, no significant group effects or group interactions on this measure at any stage of training. Mean baseline HR was 187.6 $( \pm 14.40)$ for the lesion group and $210.91( \pm 12.1)$ for the sham group.

\section{DISCUSSION}

The present results show that damage to the major thalamic projection nucleus to the prefrontal cortex, that is, the MDN, in rabbits produces a retardation in acquisition of the EB conditioned response. Several recent studies have shown similarly that damage to the mPFC also retards acquisition of the $\mathrm{EB}$ and nictitating membrane CR during trace conditioning (Kronfrost-Collins and Disterhoft 1998; Weibel et al. 2000; McLaughlin et al. 2001). However, it has been shown that simple delay or differential EB conditioning is unaffected by mPFC damage (e.g., Buchanan and Powell 1982; Weibel et al. 2000). Similarly, we have shown that MDN lesions have only a minimal or no effect on delay EB conditioning. Using a .5-sec ISI, for example, Buchanan and Thompson (1990) found a mild, but significant, impairment of EB conditioning, which, however, occurred only on the first session of training in MDN lesion compared with sham lesion rabbits. Buchanan et al. (1997b) also reported a mild deficit, which, in this case, was not statistically significant in MDN damaged rabbits by use of a delay paradigm with a 1.0-sec ISI. These two studies thus suggest that damage to the MDN, like its projection cortex, the MPFC, has only minimal, if any, effects on Pavlovian EB conditioning when delay procedures are used. However, as the present results show, trace conditioning is retarded by MDN damage.

We have reported previously that MDN lesions also have small, but systematic, effects on the heart rate CR, in that MDN-lesioned animals tended to show larger and longer-lasting conditioned heart rate decelerations than did sham-lesioned animals (Buchanan and Thompson 1990). We have interpreted this effect as being due to the release of sympathetic control by MDN damage (Huang et al. 1988). However, this effect in the present study was small and not statistically significant. This is probably a function of the

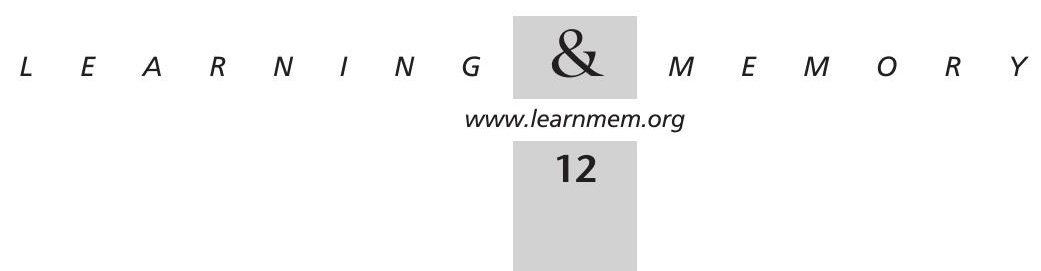




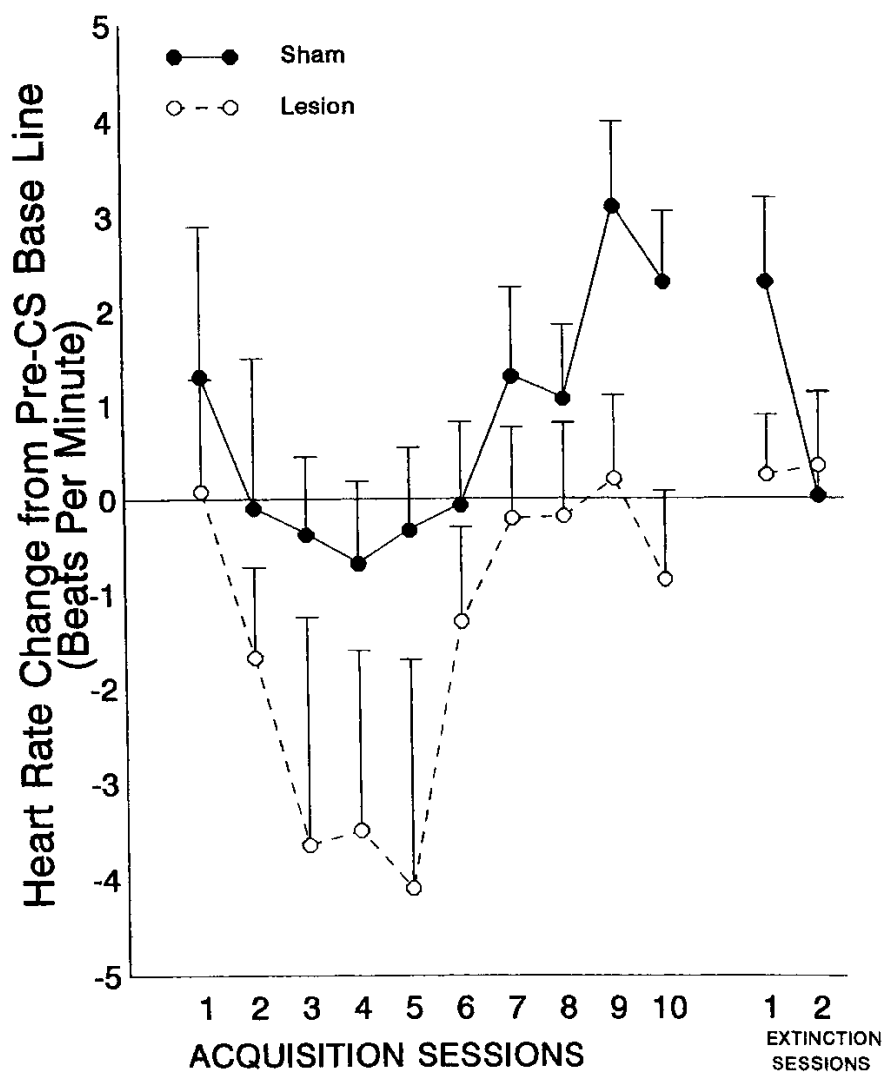

Figure 3 Mean heart rate change from pre-CS baseline $( \pm$ SE) averaged across 10 post-CS interbeat intervals as a function of 10 acquisition sessions and 2 extinction sessions during trace conditioning with a .5-sec conditioned stimulus (CS), a .5-sec trace period, and a 50-msec periorbital shock unconditioned stimulus (US). Data are shown in beats per minute (BPM) and represent the average of $10 \mathrm{IBIs}$ after CS onset during four nonreinforced test trials in which the US was omitted.

fact that the manipulations in the present experiment tend to yield larger HR decelerations in normal animals, which could obscure any difference between sham and MDN-lesioned animals. Increasing the ISI increases the magnitude of the decelerative HR CR in normal animals (e.g., see Powell et al. 1974), due to the increased time for the response to completely develop. In previous studies, the primary effect of MDN lesions appeared to be not on the decelerative component of the HR CR, but on a later-occurring accelerative component, which appears after several days of training, and which is associated with consistent performance of the eyeblink CR (Buchanan and Thompson 1990). In the present study, these conditioned HR accelerations were also abolished, but the decelerative component was also fairly large in the lesion group, although the group differences were not statistically significant. Variability was, however, greater in the lesion group, probably due to variations in the lesion sites. Thus, larger $n$ 's might have resulted in significant differences in the HR response as well.
It has been reported previously that lesions of MDN interfere with various types of learning tasks (Markowitsch 1982; Zola-Morgan and Squire 1985; Squire 1986; Robinson and Mair 1992). For example, MDN lesions cause a mild, but significant, impairment in discriminative responding in a running wheel avoidance task, and also decrease training-related multiple-unit activity in MDN projection cortex (Gabriel et al. 1989). Other discriminative/reversal deficits following MDN damage have also been reported (Weis and Means 1980; Staubli et al. 1987; Lu and Slotnick 1990). Additionally, some investigators report that tests of spatial memory are sensitive to MDN damage (Means et al. 1975; Kessler et al. 1982; Stokes and Best 1988, 1990), although others report no effect on such tasks (Hunt and Aggleton 1991). The effects of MDN damage have been interpreted variously as affecting primarily the early, encoding stages of learning (e.g., Gabriel et al. 1989; Hunt and Aggleton 1991), working memory (e.g., Gaffan and Murray 1990; Gaffan and Watkins 1991; M'Harzi et al. 1991), or other more nonspecific activity, such as motor processes (Vanderwolf 1971; Vives and Mogensen 1985; Swerdlow and Koob 1987; Ray and Price 1992), attentional phenomena (Stokes and Best 1990; Bouyer et al. 1992), or autonomic mechanisms (West and Benjamin 1983; Buchanan and Powell 1986; Huang et al. 1988; Varner et al. 1988).

Devinsky et al. (1995) suggested recently that the MDN projection cortex (referred to by these authors as anterior cingulate cortex, but which we have termed the medial prefrontal cortex; mPFC) is important for visceromotor control, and may also participate in a response selection process, particularly in situations requiring novel response choices. They suggest that this area of the cortex is involved in early stimulus processing (as would be reflected in the HR CR), and in preparation for motor responses (such as the EB CR), but is not involved in long-term storage of information. They further suggest that these two functions (i.e., visceromotor control and response selection) may be coactivated when appropriate, as in learning situations. In the rabbit $\mathrm{EB}$ and $\mathrm{HR}$ classical conditioning model utilized here, mPFC appears necessary for acquisition of conditioned HR changes (e.g., Buchanan and Powell 1982; Powell et al. 1994), but does not appear necessary for EB CR acquisition. Damage to MDN, on the other hand, only minimally affects HR CR acquisition, but significantly impairs EB CR acquisition. We have suggested previously that these results implicate MDN in the response selection function of mPFC described by Devinsky et al. (1995), but less directly in the visceromotor function (Buchanan and Thompson 1990; Chachich et al. 1997).

That MDN may be involved in such a process, is based on several lines of evidence. First, as noted above, unlike the $\mathrm{mPFC}, \mathrm{MDN}$ appears to be involved in mediating sym-

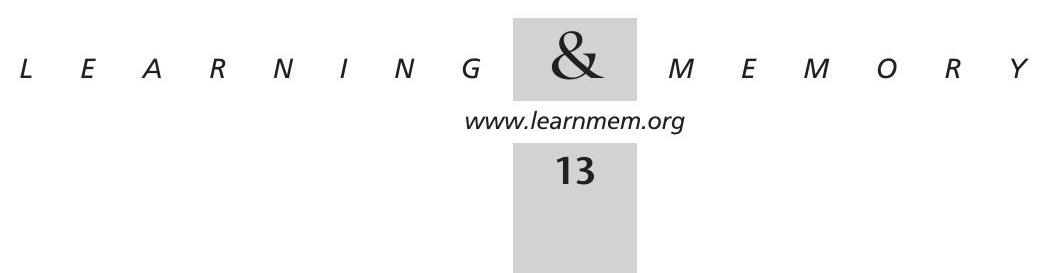


pathetic responses to CSs, which may provide the cardiovascular support required for execution of a learned somatomotor response (e.g., see Buchanan and Powell 1986; Huang et al. 1988; Varner et al. 1988). Second, lesions of MDN interfere with somatomotor learning in a variety of learning models, as noted above. Third, it was shown recently that MDN in the rat receives GABA inputs from a variety of forebrain sources; moreover, when activated by GABA agonists, these cells produced dose-dependent increases in locomotion (Churchill et al. 1996a,b), thus implicating MDN in somatomotor activity. It is important to note, however, that the acquisition, shaping, and storage of the motor programs underlying such skeletal responses is almost certainly not associated with either the PFC or its thalamic connections; current evidence suggests that extrapyramidal motor structures may provide a substrate for this kind of somatomotor plasticity (Powell et al. 1978; Thompson et al. 1983; Kao and Powell 1988; Thompson 1991). Based on this model, interference with learned somatomotor responses by MDN damage would be due to MDN's participation in a PFC-mediated response selection process rather than in the acquisition of the specific somatomotor response per se (see Kolb 1984; Fuster 1989; Devinsky et al. 1995).

It is important to note that the proposed response selection process occurs well before overt movement (viz., it is pre-motor), and represents a level of processing that determines whether or not a response is necessary, and the correct response, if one is required (Devinsky et al. 1995). It has also been suggested that this process is particularly important in situations involving motivationally significant stimuli (Heimer et al. 1982), such as the CS and US in classical conditioning. The proposed involvement of MDN in a response selection process is therefore independent of any direct skeletomotor function. This is consistent with our earlier finding that MDN lesions have no effect on $\mathrm{EB}$ unconditioned responses, or on HR URs (Buchanan and Thompson 1990). Also, in the present study, there were no lesion effects on CR or UR amplitude, suggesting that there was no impairment in the lesioned animals' ability to execute the $\mathrm{EB}$ responses. Thus, we suggest that MDN activity during classical conditioning is not directly involved in acquisition of learned skeletal behaviors, but may be related importantly to concomitantly occurring autonomic changes that are integrated with other kinds of information to produce adaptive somatomotor behaviors in order to deal effectively with complex stimulation. Clearly, there must be a CNS interface between structures involved in information processing and those involved in generating the adaptive behaviors that ultimately occur as a result of such processing. The thalamic-PFC axis may provide such an interface by participating in a somatomotor response selection process, as alluded to above.

However, the degradation of this system by interfer- ence with MDN's input to the MPFC appears to have only a small effect until the task is rendered more difficult by the use of nonoptimal learning parameters. A similar analysis has been suggested for the role of the hippocampal complex in classical conditioning. Thus, hippocampal lesions do not affect simple delay eyeblink conditioning using optimal stimulus parameters (Schmaltz and Theios 1972; Powell and Buchanan 1980), although CS-evoked increases in hippocampal neuronal activity closely follow the pattern and timing of the eyeblink CR (Berger and Thompson 1978). The resolution of this conflicting evidence appears to have been generated by later research showing that other types of eyeblink conditioning, using more difficult or nonoptimal parameters (e.g., trace conditioning or differential eyeblink conditioning and reversal), are impaired by hippocampal lesions (Buchanan and Powell 1980; Moyer et al. 1990). The present results clearly support a similar interpretation of MDN function, although these two structures are unlikely to play identical roles in EB conditioning. Both, however, appear to modulate such conditioning under certain circumstances.

The necessary and sufficient CNS substrates for acquisition and performance of the EB CR are known to be in the cerebellum, that is, the interpositus nucleus (see Thompson 1991). Recent neuroanatomical studies have shown connections between the cerebellum and MDN. Thus, it is possible that a mPFC/cerebellar/thalamic module is necessary for efficient acquisition of the EB CR during trace and reversal conditioning. Such models have been proposed by other investigators (e.g., Houk and Wise 1995; Weiss and Disterhoft 1996). These models include MDN and the ventral thalamic nuclei as major thalamic centers in this circuit. Although the precise mechanism for these effects are not clearly understood, it is assumed by most that under ideal conditions, that is, when the acquisition parameters are optimal for acquisition of the response, limbic system input from the hippocampus and other limbic structures is not necessary for the memory trace to be carried through the interstimulus interval. However, during trace procedures in which the CS is not physically present to activate appropriate memory mechanisms, hippocampal input to extrapyramidal structures (which we believe is through the subiculum-mPFC-neostriatal connections) is necessary for the memory trace to persist through the trace period. As noted, connections also exist between the hippocampus and the mPFC (e.g., Swanson 1981), which suggests that information concerning the status of environmental and somatomotor response selection mechanisms may be routed through the hippocampus and $\mathrm{MPFC}$ to the cerebellum, and back to PFC through the thalamus to modify the output of the cerebellur nuclei that determine acquisition of the EB CR under conditions that require limbic/cortical processing, that is, trace conditioning. In any case, it is clear that MDN participates in trace, but not in delay conditioning. The specific

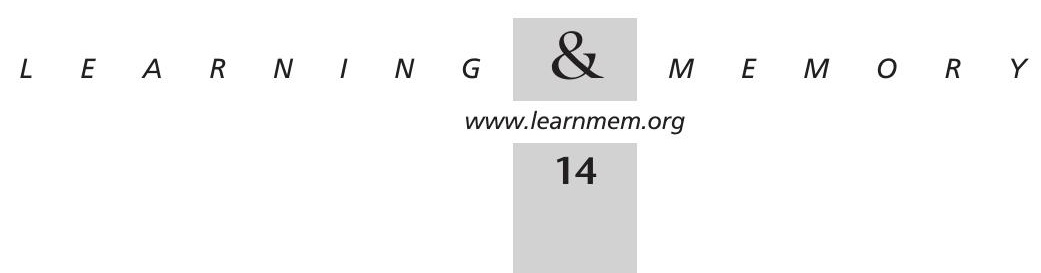


circuits underlying this effect are unknown, but the structures involved almost certainly include those described by Weiss and Disterhoft (1996), as well as others (e.g., Houk and Wise 1995).

\section{MATERIALS AND METHODS}

\section{Subjects and Surgery}

Animals were male $(n=10)$ and female $(n=11)$ New Zealand albino rabbits obtained from a USDA-licensed supplier. Animals were maintained in an AAALAC-accredited animal facility with a 12:12 $\mathrm{h}$ light/dark cycle; lights on at 7:00 am. Food and water were available ad libitum. All behavioral testing was conducted during the daylight portion of the light/dark cycle. All USPHS regulations regarding animal welfare were followed.

All surgery was performed under aseptic surgical conditions. Animals were anesthetized with ketamine hydrochloride $(55 \mathrm{mg} / \mathrm{kg}$ i.m.) supplemented by acepromazine malate $(2.2 \mathrm{mg} / \mathrm{kg}$ i.m.) and xylazine (3.0 mg/kg i.m.). Ibotenic acid (Sigma), dissolved in phosphate buffer ( $\mathrm{pH} 7.4,10 \mathrm{mg} / \mathrm{mL}$ ), was used to lesion cell bodies in MDN. Lesion injections were made with a Hamilton $1 \mu \mathrm{L}$ syringe. Two injections were made on each side of the brain $(\mathrm{P}=2$, $\mathrm{L}= \pm 1.5, \mathrm{~V}=9.5$, and $\mathrm{P}=3, \mathrm{~L}= \pm 2, \mathrm{~V}=9.5$, with reference to bregma, the midline suture, and dura, respectively). Each injection consisted of $0.5 \mu \mathrm{L}$ (i.e., $5 \mu \mathrm{g}$ ) injected over a 20 -min period. After surgery, the animals were treated with Nubain and allowed a 2-3wk recovery period before behavioral testing began. Sham control animals were anesthetized, and holes drilled in the skull, as for the lesioned subjects, but no further manipulation took place.

\section{Apparatus and Procedure}

Experimental contingencies were controlled by a PC-based data acquisition system (MACRO, Inc.) supplemented by solid state transistor-transistor logic (TTL) programming devices. Heart rate and eyeblink responses were recorded on a Grass Model 7 polygraph equipped with appropriate preamplifiers. During conditioning, the output of the polygraph was connected to the computer, in which A-D conversion was performed in real time. The shock US was delivered by a Grass Model S88 stimulator equipped with constant current and stimulus isolation. During the experiment, animals were restrained in Plexiglas rabbit restrainers (Gormezano 1966) in ventilated, sound- and light-attenuating commercial animal enclosures (Industrial Acoustics Co.). The CS was a $1216-\mathrm{Hz}, 75-\mathrm{dB}$ tone; a 50-msec, 2-mA, 200-Hz AC electric shock train was the US. The US was delivered periorbitally through previously implanted stainlesssteel wound clips. Each session consisted of 60 CS-US pairings with an intertrial interval of $60( \pm 15)$ sec. After 2 d of adaptation to restraint in the experimental chamber, each animal received 10 consecutive days of acquisition training followed by $2 \mathrm{~d}$ of extinction. Except for test trials (see below), during acquisition, the CS was presented for .5-sec. A .5-sec trace period, then followed, at which time the 50 -msec periorbital shock was presented. During extinction, the shock US was omitted so that the tone was presented alone. Eyeblink was measured via electrodes consisting of Tru-chrome dental wire acutely inserted over the eyelids before the beginning of each session. Insertion of these electrodes caused neither apparent discomfort nor any signs of infection or irritation (Buchanan and Thompson 1990). Leads for the EB electrodes were connected to a Grass Model 7P3 preamplifier and integrator set in its integrator mode. The preamplifier was calibrated so that a 100$\mu \mathrm{V}$ change across the electrodes corresponded to a $1-\mathrm{mm}$ deflec- tion of the appropriate oscillograph pen. Stainless-steel safety pins inserted subcutaneously over the left hind flank and right foreleg served as electrocardiographic (EKG) recording electrodes. Leads from these pins were connected to a Grass Model 7 P4F EKG preamplifier. During conditioning, all EB and HR responses were recorded by the A-D converter of the computer, which sampled at $3000 \mathrm{~Hz}$, beginning $4 \mathrm{sec}$ before tone onset and continuing for 1 sec after tone termination, except on four test trials (trials 1, 10, 30, and 50), on which the CS was presented but was not followed by the shock US. During these test trials, the ECG was recorded beginning $4 \mathrm{sec}$ before tone onset and continuing until $4 \mathrm{sec}$ after tone onset. These test trials were utilized to allow for measurement of the complete expression of the HR response, which is only possible in the absence of the shock US.

\section{Histology}

Animals were sacrificed with pentobarbital and perfused with physiological saline and $10 \%$ formalin; $40-\mu \mathrm{m}$ sections throughout the lesions were stained with thionin. The lesions were then located microscopically and line drawings made of the appropriate sections using a Leitz drawing tube and microscope. The extent of the lesion was then determined by superimposing these drawings onto plates from the atlas of Shek et al. (1986).

\section{Data Reduction and Analysis}

The criterion for an eyeblink CR was a $200-\mu \mathrm{V}$ change from baseline during CS presentation. This is equivalent to a 2-mm deflection of the appropriate polygraph pen and $\sim 1 \mathrm{~mm}$ of eyelid or nictitating membrane extension. CR latency was recorded as the time from CS onset until the eyeblink response first exceeded criterion. CR amplitude was recorded as the maximum amplitude change (in millivolts) from baseline during the CS period. Heart rate was recorded only during the four test trials as discussed above. The duration of each interbeat interval (IBI) was assessed by computer during each test trial for 10 IBIs before CS onset and 10 IBIs after CS onset. Each IBI was first converted to HR in beats per minute (BPM). The pre-CS HR values for each test trial were then averaged to yield a single baseline value. The HR conditioned response (CR) was obtained by subtracting this mean from the HR associated with each post-CS IBI. All data were analyzed by repeated measures analysis of variance (ANOVA), using as factors group (2 levels), and session (10 levels), and, additionally for HR, trial (4 levels) and post-CS IBIs (10 levels). Significant effects were further analyzed by post-hoc application of the Newman-Keuls Multiple Range Test (Edwards 1964).

\section{ACKNOWLEDGMENTS}

This research was supported by DVA Institutional Research Funds awarded to the Wm. Jennings Bryan Dorn VA Medical Center. We thank Elizabeth Hamel for manuscript preparation and Andrew Pringle for preparation of the figures. This paper is dedicated to the memory of Shirley L. Buchanan, who was preparing this study just prior to her death in June, 1998.

The publication costs of this article were defrayed in part by payment of page charges. This article must therefore be hereby marked "advertisement" in accordance with 18 USC section 1734 solely to indicate this fact.

\section{REFERENCES}

Berger, T.W. and Thompson R.F. 1978. Neuronal plasticity in the limbic

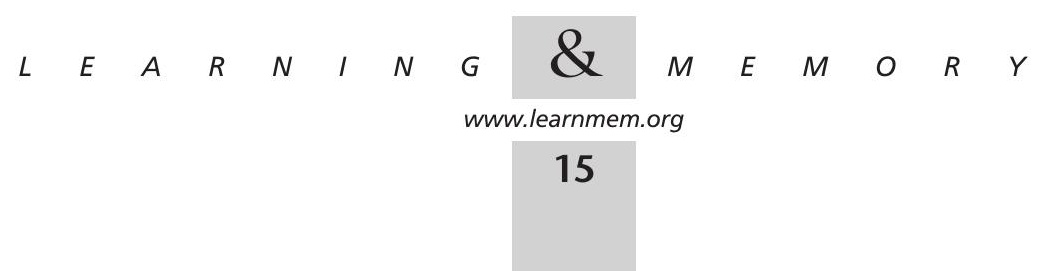


system during classical conditioning of the rabbit nictitating membrane response. I. The hippocampus. Brain Res. 145: 323-346.

Berger, T.W. and Orr, W.B. 1983. Hippocampectomy selectively disrupts discrimination reversal conditioning of the rabbit nictitating membrane response. Behav. Brain Res. 8: 49-68.

Bouyer, J.J., Montaron, M.F., Buser, P., Durand, C., and Rougeul, A. 1992. Effects of mediodorsalis thalamic nucleus lesions on vigilance and attentive behaviour in cats. Behav. Brain Res. 51: 51-60.

Buchanan, S.L. 1991. Differential and reversal Pavlovian conditioning in rabbits with mediodorsal thalamic lesions: Assessment of heart rate and eyeblink responses. Exp. Brain Res. 86: 174-181.

. 1994. Mediodorsal thalamic lesions impair acquisition of an eyeblink avoidance response in rabbits. Behav. Brain Res. 65: $173-179$

Buchanan, S.L. and Powell, D.A. 1980. Divergencies in Pavlovian conditioned heart rate and eyeblink responses produced by hippocampectomy in the rabbit. Behav. Neural Biol. 30: 20-38.

. 1982. Cingulate cortex: Its role in Pavlovian conditioning. $J$. Comp. Physiol. Psychol. 96: 755-774.

. 1986. Electrical stimulation of anteromedial and mediodorsal thalamus elicits differential cardiovascular response patterns from conscious rabbits. Physiol. Psychol. 14: 115-123.

Buchanan, S.L. and Thompson, R.H. 1990. Mediodorsal thalamic lesions and Pavlovian conditioning of heart rate and eyeblink responses in the rabbit. Behav. Neurosci. 104: 912-918.

Buchanan, S.L., Beylotte, III, F.M., and Powell, D.A. 1997a. Lesions of the thalamic reticular nucleus or the basal forebrain impair Pavlovian eyeblink conditioning and attenuate learning-related multiple-unit activity in the mediodorsal nucleus of the thalamus. Psychobiology 25: $48-58$.

Buchanan, S.L., Penney, J., Tebbutt, D., and Powell, D.A. 1997b. Lesions of the mediodorsal nucleus of the thalamus and classical eyeblink conditioning under less than optimal stimulus conditions: Role of partial reinforcement and interstimulus interval. Behav. Neurosci. 111: $1075-1085$.

Chachich, M., Buchanan, S., and Powell, D.A. 1997. Characterization of single-unit activity in the mediodorsal nucleus of the thalamus during expression of differential heart rate conditioning in the rabbit. Neurobiol. Learn. \& Mem. 67: 129-141.

Churchill, L., Zahm, D.S., Duffy, P., and Kalivas, P.W. 1996a. The mediodorsal nucleus of the thalamus in rats - II. Behavioral and neurochemical effects of GABA agonists. Neuroscience 70: 103-112.

Churchill, L., Zahm, D.S., and Kalivas, P.W. 1996b. The mediodorsal nucleus of the thalamus in rats-I. Forebrain gabaergic innervation. Neuroscience 70: 93-102.

Devinsky, O., Morrell, M.J., and Vogt, B.A. 1995. Contributions of anterior cingulate cortex to behaviour. Brain 118: 279-306.

Edwards, A.L. 1964. Experimental design in psychological research. Holt, Rinehart, and Winston, New York, NY.

Fuster, J.M. 1989. The prefrontal cortex: Anatomy, physiology and neuropsychology of the frontal lobe. 2nd ed., Raven Press, New York, NY.

Gabriel, M., Sparenborg, S., and Kubota, Y. 1989. Anterior and medial thalamic lesions, discriminative avoidance learning, and cingulate cortical neuronal activity in rabbits. Exp. Brain Res. 76: 441-457.

Gaffan, D. and Murray, E.A. 1990. Amygdalar interaction with the mediodorsal nucleus of the thalamus and the ventromedial prefrontal cortex in stimulus-reward associative learning in the monkey. $J$. Neurosci. 10: 3479-3493

Gaffan, D. and Watkins, S. 1991. Mediodorsal thalamic lesions impair long-term visual associative memory in macaques. Eur. J. Neurosci. 3: 615-620.

Gormezano, I. 1966. Classical conditioning. In Experimental methods and instrumentation in psychology. (ed. J.B. Sidowski), pp. 385-420. McGraw Hill, New York, NY.

Heimer, L., Switzer, R.D., and Van Hoesen, G.W. 1982. Ventral striatum and ventral pallidum: Components of the motor system? Trends Neurosci. 5: 83-87.
Houk, J.C. and Wise, S.P. 1995. Distributed modular architectures linking basal ganglia, cerebellum, and cerebral cortex: Their role in planning and controlling action. Cerebral Cortex 5: 95-110.

Huang, Z., Varner, K.J., Barman, S.M., and Gebber, G.L. 1988. Diencephalic regions contributing to sympathetic nerve discharge in anesthetized cats. Am. J. Pbysiol. 254: R249-R256.

Hunt, P.R. and Aggleton, J.P. 1991. Medial dorsal thalamic lesions and working memory in the rat. Behav. Neural Biol. 55: 227-246.

Kao, K. and Powell, D.A. 1988. Lesions of the substantia nigra retard Pavlovian eyeblink but not heart rate conditioning in the rabbit. Behav. Neurosci. 102: 515-525.

Kessler, J., Markowitsch, H.J., and Otto, B. 1982. Subtle but distinct impairments of rats with chemical lesions in the thalamic mediodorsal nucleus, tested in a radial arm maze. J. Comp. Physiol. Psychol. 96: $712-720$.

Kolb, B. 1984. Functions of the frontal cortex of the rat: A comparative review. Brain Res. Rev. 8: 65-98.

Kronforst-Collins, M.A. and Disterhoft, J.F. 1998. Lesions of the caudal area of rabbit medial prefrontal cortex impair trace eyeblink conditioning. Neurobiol. Learn. \& Mem. 69: 147-162.

Lu, X.M. and Slotnick, B.M. 1990. Acquisition of an olfactory learning-set in rats with lesions of the mediodorsal thalamic nucleus. Chem. Senses 15: 713-724.

M'Harzi, M., Jarrard, L.E., Willig, F., Palacios, A., and Delacour, J. 1991. Selective fimbria and thalamic lesions differentially impair forms of working memory in rats. Behav. Neural Biol. 56: 221-239.

Markowitsch, H.J. 1982. Thalamic mediodorsal nucleus and memory: A critical evaluation of studies in animals and man. Neurosci. Biobehav. Rev. 6: 351-380

McLaughlin, J., Skaggs, H., Churchwell, J., and Powell, D.A. 2001. Medial prefrontal cortex and Pavlovian conditioning: Trace versus delay conditioning. Behav. Neurosci. (in press, 2002)

Means, L.W., Hershey, A.E., Waterhouse, G.W., and Lane, C.S. 1975 Effects of dorsomedial thalamic lesions on spatial discrimination reversal in the rat. Physiol. Behav. 14: 725-729.

Moyer, Jr., J.R., Deyo, R.A., and Disterhoft, J.F. 1990. Hippocampectomy disrupts trace eye-blink conditioning in rabbits. Behav. Neurosci. 104: $243-252$.

Powell, D.A. and Milligan, W.L. 1975. Effects of partial and continuous reinforcement on conditioned heart rate and corneoretinal potential responses in the rabbit (Oryctolagus cuniculus). Psychol. Record 25: 419-426.

Powell, D.A. and Buchanan, S.L. 1980. Autonomic-somatic relationships in the rabbit (Oryctolagus cuniculus): Effects of hippocampal lesions. Physiol. Psychol. 8: 455-462.

Powell, D.A., Lipkin, M., and Milligan, M.L. 1974. Concomitant changes in classically conditioned heart rate and corneoretinal potential discrimination in the rabbit (Oryctolagus cuniculus). Learn. \& Motiva. 5: 532-547.

Powell, D.A., Mankowski, D., and Buchanan, S.L. 1978. Concomitant heart rate and corneoretinal potential conditioning in the rabbit (Oryctolagus Cuniculus): Effects of caudate lesions. Physiol. Bebav. 20: $143-150$.

Powell, D.A., Watson, K., and Maxwell, B. 1994. Involvement of subdivisions of the medial prefrontal cortex in learned cardiac adjustments. Behav. Neurosci. 108: 294-307.

Ray, J.P. and Price, J.L. 1992. The organization of the thalamocortical connections of the mediodorsal thalamic nucleus in the rat, related to the ventral forebrain-prefrontal cortex topography. J. Comp. Neurol. 323: $167-197$.

Robinson, J.K. and Mair, R.G. 1992. MK-801 prevents brain lesions and delayed-nonmatching-to-sample deficits produced by pyrithiamine-induced encephalopathy in rats. Behav. Neurosci. 106: 623-633

Schmaltz, L.W. and Theios, J. 1972. Acquisition and extinction of a classically conditioned response in hippocampectomized rabbits (Oryctolagus cuniculus). J. Comp. Physiol. Psychol. 79: 328-333. 
Shek, J.W., Wen, G.Y., and Wisniewski, H.M. 1986. Atlas of the rabbit brain and spinal cord. Karger, New York, NY.

Solomon, P.R., Vander Schaaf, E., Thompson, R.F., and Weisz, D.J. 1986. Hippocampus and trace conditioning of the rabbit's classically conditioned nictitating membrane response. Behav. Neurosci. 100: 729-744

Squire, L.R. 1986. Mechanisms of memory. Science 232: 1612-1619.

Staubli, U., Schottler, F., and Nejat-Bina, D. 1987. Role of dorsomedial thalamic nucleus and piriform cortex in processing olfactory information. Behav. Brain Res. 25: 117-129.

Stokes, K.A. and Best, P.J. 1988. Mediodorsal thalamic lesions impair radial maze performance in the rat. Behav. Neurosci. 102: 294-300.

_. (1990). Mediodorsal thalamic lesions impair "reference" and "working" memory in rats. Physiol. Behav. 47: 471-476.

Swanson, L.W. 1981. A direct projection from Ammon's horn to prefrontal cortex in the rat. Brain Res. 217: 150-154.

Swerdlow, N.R. and Koob, G.F. 1987. Lesions of the dorsomedial nucleus of the thalamus, medial prefrontal cortex and pedunculopontine nucleus: Effects on locomotor activity mediated by nucleus accumbens-ventral pallidal circuitry. Brain Res. 412: 233-243.

Thompson, R.F. 1991. Are memory traces localized or distributed? Neuropsychologia 29: 571-582.

Thompson, R.F., McCormick, D.A., Lavond, D.G., Clark, G.A., Kettner, R.E., and Mauk, M.D. 1983. The engram found? Initial localization of the memory trace for a basic form of associative learning. In Progress in psychobiology and physiological psychology. (ed. J.L. Sprague and A.N. Epstein), pp. 167-196. Academic Press, New York, NY.
Vanderwolf, C.H. 1971. Limbic-diencephalic mechanisms of voluntary movement. Psychol. Rev. 78: 83-113.

Varner, K.J., Barman, S.M., and Gebber, G.L. 1988. Cat diencephalic neurons with sympathetic nerve-related activity. Am. J. Pbysiol. 254: R257-267.

Vives, F. and Mogenson, G.J. 1985. Electrophysiological evidence that the mediodorsal nucleus of the thalamus is a relay between the ventral pallidum and the medial prefrontal cortex in the rat. Brain Res. 344: 329-337.

Weible, A.P., McEchron, M.D., and Disterhoft, J.F. 2000. Cortical involvement in acquisition and extinction of trace eyeblink conditioning. Behav. Neurosci. 114: 1058-1067.

Weis, B.J. and Means, L.W. 1980. A comparison of the effects of medial frontal, dorsomedial thalamic, and combination lesions on discrimination and spontaneous alternation in the rat. Physiol. Psychol. 8: 325-329.

Weiss, C. and Disterhoft, J.F. 1996. Eyeblink conditioning, motor control, and the analysis of limbic-cerebellar interactions. Behav. Brain Sci. 19: 479-527.

West, C.H.K. and Benjamin, R.M. 1983. Effects of stimulation of the mediodorsal nucleus and its projection cortex on heart rate in the rabbit. J. Auto. Nervous Sys. 9: 547-557.

Zola-Morgan, S. and Squire, L.R. 1985. Medial temporal lesions in monkeys impair memory on a variety of tasks sensitive to human amnesia. Behav. Neurosci. 99: 22-34.

Received November 8, 2001; accepted in revised form January 24, 2002. 


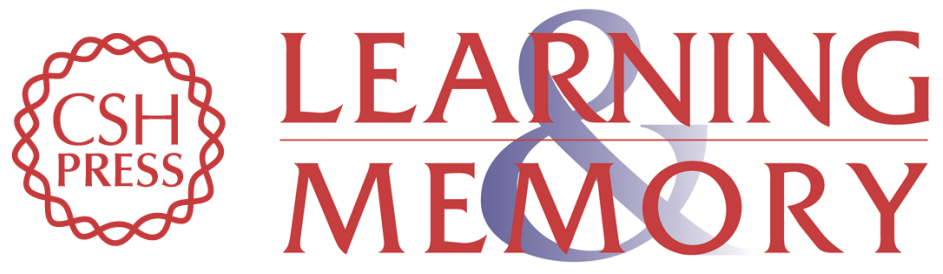

\title{
Mediodorsal Thalamic Lesions Impair Trace Eyeblink Conditioning in the Rabbit
}

\author{
Donald A. Powell and John Churchwell
}

Learn. Mem. 2002, 9:

Access the most recent version at doi:10.1101/lm.45302

References This article cites 51 articles, 2 of which can be accessed free at: http://learnmem.cshlp.org/content/9/1/10.full.html\#ref-list-1

License

Email Alerting Receive free email alerts when new articles cite this article - sign up in the box at the Service top right corner of the article or click here. 